\title{
Knowledge, attitude and practice of traditional medicine among people of Jos South Local Government Area of Plateau State, Nigeria
}

\author{
Temitayo Lucia OHEMU ${ }^{*}$, David SHALKUR ${ }^{2}$, Benson Okpe OHEMU ${ }^{3}$ and Peter \\ DANIEL ${ }^{1}$
}

\author{
${ }^{1}$ Department of Pharmacognosy, Faculty of Pharmaceutical Sciences, University of Jos, Nigeria. \\ ${ }^{2}$ Department of Clinical Pharmacy, Faculty of Pharmaceutical Sciences, University of Jos, Nigeria. \\ ${ }^{3}$ Society for Family Health, Abuja, FCT, Nigeria.
}

Received $2^{\text {nd }}$ January 2021; Accepted 28 ${ }^{\text {th }}$ April 2021

\begin{abstract}
Studies and documentation on the current knowledge and practices of traditional medicine among African communities are lacking particularly in this era of modern health care expansion. This study aimed at assessing the knowledge, attitude and practice of traditional medicine in Jos South Local Government Area (LGA) of Plateau State, Nigeria. A systemic random sampling technique was employed for this study. A semi-structured open and closed ended questionnaire was used to collect data through house to house interview among 300 participants identified for the study. The data was then analysed using Statistical Package for Social Sciences (SPSS) Version 20.0 (Chicago, SPSS Inc.). The studies revealed two hundred and seventy four $(94.8 \%)$ have heard about traditional medicine, while two hundred and forty two $(83.7 \%)$ of them have used traditional medicine once or more in their life time, especially for the treatment of malaria and fever. One hundred and eleven $(38.4 \%)$ of the respondents preferred using both traditional and modern medicine. The prevalence of Traditional Medicine patronage in Jos South LGA, Plateau state is high and this may be related to the socio-cultural acceptability, easy accessibility, and affordability of Traditional Medicine.
\end{abstract}

Keywords: Knowledge; Attitude; Practice; Traditional Medicine; Nigeria

\section{INTRODUCTION}

Since the beginning of human civilization, medicinal plants have been used by mankind for its therapeutic value. For thousands of years, Natural products (plants, minerals and animals) have been a major source of medicines, as several modern drugs have been isolated from it [1]. The traditional medicine system continues to play an essential role in the health care system, with about $80 \%$ of the world's inhabitants relying mainly on it for their primary health care [2,3]. Traditional Medicine (TM) enjoys wider acceptability among the people of developing countries than modern medicine because it blends readily with the sociocultural life of the people. There has also been increasing popularity of TM in developed countries because of its diversity, flexibility, relatively low cost, low level of technological inputs, and relatively low side

*Correspondence. E-mail: tayogb17@gmail.com Tel: +234-8036575405.

ISSN 0189-8442

2021. Published by Faculty of Pharmaceutical Sciences, University of Jos, Nigeria. Under Creative Commons Attribution-Non-Commercial 4.0 International License. https://creativecommons.org/licenses/by-nc/4.0/ 
effects [4-6]. A study in Nigeria showed that herbal medicine is the first choice for home treatment of nearly two-thirds of children with hay fever [7]. The practices across Africa tend to be characterized by a holistic and highly individualized approach to treatment. Emphasis is based on maximizing the body's inherent healing ability, by involving patients as active participants in their own care, while addressing the physical, mental, spiritual, and supernatural attributes of a disease $[8,9]$. The World Health Organisation (WHO) has acknowledged that "traditional, complementary, or alternative medicine has many positive features, and that traditional medicine and its practitioners play an important role in treating chronic illnesses, and improving the quality of life of those suffering from minor illness or from certain incurable diseases"[10].

The WHO had stated that national policies on TM, which is a major challenge facing the appropriate use of TM are needed in order to define the role of Traditional Medicine/Complimentary Alternative Medicine (TM/CAM) in national health care delivery system and how it can contribute to health sector reform. These policies will also ensure that necessary regulations and legal mechanism are in place for promoting and maintaining good practice, the authenticity, safety and efficacy of any government oversight [11].

The main purpose of this study was to identify the gaps in the knowledge, attitude, and practice of TM in Jos South Local Government, Plateau State, Nigeria through cross sectional study. Data obtained from this study will serve as a baseline for concerned governmental and non-governmental bodies to undertake intervention on the use and control of TM, as well as provide important information that can help in the development of TM policies. This study will also provide important data for further investigations by researchers.

\section{METHODS}

Study design. Descriptive cross-sectional study was adopted to capture respondents' information to assess the knowledge, attitude and practice of the community in Jos South L.G.A. towards Traditional medicine (TM).

Study area. Jos South is a Local Government Area in Plateau state, Nigeria with eleven (11) wards. It houses the Governments office in Rayfield and can then be referred to as de facto capital of Plateau state. Its headquarters is in Bukuru town. It has an area of $510 \mathrm{~km}^{2}$ and a population of 306,716 based on the 2006 census, and it is the second most populated Local Government Area in Plateau state after Jos North.

Study population. The study population consisted of adults who were 19 years and above and have been resident in the community for not less than six months.

Sampling methods and sample size calculation. A systematic random sampling technique was used to select household which was done at the intervals of six houses by lottery method, and adults of $\geq 19$ years in the households were interviewed. Sample size was calculated using sample size determination formula.

$$
n=\frac{Z^{2} p(1-p)}{d^{2}} \ldots \ldots .
$$

Where: $\mathrm{n}=$ the estimated sample size

$\mathrm{Z}=$ is the standard normal value corresponding to the desired level of confidence (1.96)

$\mathrm{d}=$ error of precision $(5 \%)$

$\mathrm{p}=$ people getting health care from traditional medicine that is $80 \%$.

Therefore, adding the non-respondent rate (20\%) the final sample size 295 but 300 was used as the sample size for the study.

The study instrument. The questionnaire was divided into four sections which included:

Section A: Socio-demography

Section B: Knowledge of the Respondents on Traditional Medicine

Section C: Attitude of Participants toward Traditional Medicine 
Section D: Practice of the study subjects on TM

The questions asked were both open and closeended. The open-ended questions were used to obtain information on the source, benefit, adverse effect and name of TM used. It also allowed participants to give multiple responses to the open-ended questions.

Data collection procedure. Data were collected using semi-structured interviewer administered questionnaire adapted from standardized questionnaires used by international organizations, national studies such as Demographic and Health Survey, and published articles in peer-reviewed journals [13]. Data were collected by trained data collectors using face-to face interview.

Data quality control. Intensive training was provided to data collectors about data collection techniques. Detailed orientation was given to the data collectors about the study before data collection procedure started. A pilot test was done on 30 (10\% of the sample population) households to validate consistency of the questions and data collection tool.

Study variables. The outcome variables of the study were knowledge, attitude, and practice of the community on TMs; while the explanatory variables were age of interviewee, monthly family income, educational status, religion, and ethnicity.

Ethical issues. Formal letter of approval was obtained from Jos South LGA secretariat. Each participants of the study was informed about confidentiality. Each participant of the study agreed to participant voluntarily. Participants were allowed to discontinue the interview when they needed. All the participants of the study declared their willingness to participate and approval was gotten by verbal consents.

Data management and analysis. Data were checked for completeness and consistency and entered into SPSS version 20 by principal investigator, cleaned and analysed. The results were presented using simple frequencies with percentages in appropriate tables and figures to display the descriptive part of the result.

\section{RESULTS}

Socio-demographic characteristics of study subjects. From a total of 300 participants who were identified for the study, 289 of them participated in the study, yielding the response rate of $96 \%$. The details socio-demographic characteristics of the respondents are as presented in Table 1.

Knowledge of the respondents on traditional medicine. Table 2 presented respondents' responses to items used to assess their knowledge on TM. Two hundred and seventy four $(94.8 \%)$ of the respondents answered that they have heard about TM and $62.3 \%$ of them knew about herbal while $10.4 \%, 10 \%, 13.1 \%$, and $4.2 \%$, knew about bone setters, traditional birth attendance, both, and others respectively. Majority of the respondents reported that they have heard about more than three types of TM, and one hundred and ninety seven $(68.2 \%)$ of them reported to have ever visited modern health care service after visiting TM practitioners. Ninety five $(32.9 \%)$ of those who visited modern healthcare facilities after visiting TMP was because of no improvement in their health, while $55(19.0 \%)$ and $36(12.5 \%)$ was because of peer influence and side effects of the orthodox drugs respectively. The highest main source of herbal product $96(33.2 \%)$ was from their relatives, with malaria $73(25.3 \%)$ and fever $72(24.9 \%)$ as the reasons as major reasons for the use of herbal products. 155 $(53.6 \%)$ believe no adverse effect in use of herbal medicine, 100 (34.6\%) experienced adverse effects while 20(6.9\%) had inexplicable adverse effect.

Attitude of participants toward traditional medicine. Table 3 showed that 189 (65.3\%) of the respondents had planned to use traditional medicine in the future with $100(34.7 \%)$ not willing to use it because of fear of side effects 
$58(20.1 \%)$, access to modern medicine 33 (11.4\%), and religion $5(1.7 \%)$ and others 14 (4.8\%). The use of traditional medicine in the community was acceptable among the respondents with 123 (42.6\%) of them who agreed and $71(24.6 \%)$ strongly agreed with it usage. Two hundred and thirty three $(80.6 \%)$ of the respondents encouraged others to use traditional medicine with few 56 (19.4\%) discouraging others from the use of the medications, based on various reasons including religion $32(11.1 \%)$, cost 82 (28.4\%), availability $77(26.6 \%)$ and others 49
(17.0\%); and many of them 227 (78.5\%) believed that there are disease that are not cured by modern medicine. Similarly, majority of the respondents $204(70.2 \%)$ considered herbal medicine as safe to use, while others 85 (29.4\%) believed otherwise, without any reason. Many linked herbal medicine safety its natural origin $240(83.0 \%)$, efficacy 35 $(12.1 \%)$ and lack of adverse effects 14 (4.8\%). On a generally note, $239(83.7 \%)$ of the respondents accepts traditional medicine practices with only $50(17.3 \%)$ not accepting the practice.

Table 1: Socio-demographic characteristics $(\mathrm{N}=289)$

\begin{tabular}{|c|c|c|c|}
\hline & Variable & Frequency & Percentage \\
\hline \multirow{5}{*}{ Age group (in years) } & $19-28$ & 161 & 55.7 \\
\hline & $29-38$ & 53 & 18.3 \\
\hline & $39-48$ & 32 & 11.1 \\
\hline & $49-58$ & 30 & 10.4 \\
\hline & $\geq 59$ & 13 & 04.5 \\
\hline \multirow{4}{*}{ Marital status } & Married & 105 & 36.3 \\
\hline & Separated/divorced & 4 & 1.4 \\
\hline & Widow/ Widower & 15 & 5.2 \\
\hline & Single & 165 & 57.1 \\
\hline \multirow{8}{*}{ Occupation } & Housewife & 19 & 6.6 \\
\hline & Farmer & 22 & 7.6 \\
\hline & Government employee & 30 & 10.4 \\
\hline & Private employee & 25 & 8.7 \\
\hline & Business man/woman & 39 & 13.5 \\
\hline & Student & 128 & 44.3 \\
\hline & Unemployed & 24 & 8.3 \\
\hline & Others & 2 & 00.7 \\
\hline \multirow{4}{*}{ Ethnicity } & Hausa & 91 & 31.5 \\
\hline & Yoruba & 43 & 14.9 \\
\hline & Igbo & 49 & 17.0 \\
\hline & Others & 101 & 34.6 \\
\hline \multirow{3}{*}{$\begin{array}{l}\text { Family income per } \\
\text { month (Naira) }\end{array}$} & $<10,000$ & 57 & 19.7 \\
\hline & $<50,000$ & 115 & 39.8 \\
\hline & $>50,000$ & 110 & 38.1 \\
\hline \multirow{4}{*}{ Family size } & $1-2$ & 19 & 6.6 \\
\hline & $3-4$ & 80 & 27.7 \\
\hline & $5-6$ & 110 & 38.1 \\
\hline & $>7$ & 76 & 26.3 \\
\hline \multirow{4}{*}{$\begin{array}{l}\text { Highest Education } \\
\text { Level }\end{array}$} & None & 28 & 9.7 \\
\hline & Primary & 29 & 10.0 \\
\hline & Secondary & 77 & 26.6 \\
\hline & Higher education & 155 & 53.6 \\
\hline \multirow{4}{*}{ Religion } & Traditional & 22 & 7.6 \\
\hline & Christian & 186 & 64.4 \\
\hline & Muslim & 79 & 27.3 \\
\hline & Others & 2 & 00.7 \\
\hline
\end{tabular}


T.L. Ohemu et al. / J. Pharmacy \& Bioresources 18(2), 147-154 (2021)

Table 2: Knowledge of the study subjects on traditional medicine ( $\mathrm{N}=289)$

\begin{tabular}{|c|c|c|c|}
\hline & Variable & Frequency & $\%$ \\
\hline \multirow{2}{*}{ Have you ever heard about TM? } & Yes & 274 & 94.8 \\
\hline & No & 15 & 5.2 \\
\hline \multirow{5}{*}{ Which one do you know? } & Herbal medicine & 180 & 62.3 \\
\hline & Bone setters & 30 & 10.4 \\
\hline & Traditional birth attendance & 29 & 10 \\
\hline & All & 38 & 13.1 \\
\hline & Others/specify & 12 & 4.2 \\
\hline \multirow{3}{*}{$\begin{array}{l}\text { Have you or any person you know visited modern } \\
\text { health care service soon after visiting TM practitioner? }\end{array}$} & Yes & 197 & 68.2 \\
\hline & No & 92 & 31.8 \\
\hline & No improvement & 95 & 32.9 \\
\hline \multirow{3}{*}{ Why he or she did? } & Peer influence & 55 & 19.0 \\
\hline & Side effect & 36 & 12.5 \\
\hline & Other & 31 & 10.7 \\
\hline \multirow{5}{*}{ What were the main sources of herbal products? } & From practitioners & 89 & 30.8 \\
\hline & Relatives & 96 & 33.2 \\
\hline & Neighbour & 24 & 8.3 \\
\hline & Friends & 25 & 8.7 \\
\hline & Themselves & 37 & 12.8 \\
\hline \multirow{7}{*}{ Why did you use herbal medicine? } & Fever & 72 & 24.9 \\
\hline & Malaria & 73 & 25.3 \\
\hline & Hypertension & 13 & 4.5 \\
\hline & Diabetes & 26 & 9.0 \\
\hline & Infection & 38 & 13.1 \\
\hline & Constipation & 26 & 9.0 \\
\hline & Others/specify & 29 & 10.0 \\
\hline \multirow{4}{*}{ What do you know about adverse effect of TM } & No adverse effect & 155 & 53.6 \\
\hline & $\begin{array}{l}\text { Had adverse effect like skin } \\
\text { rash, vomiting, dizziness }\end{array}$ & 100 & 34.6 \\
\hline & $\begin{array}{l}\text { Users experienced } \\
\text { inexplicable adverse effects }\end{array}$ & 20 & 6.9 \\
\hline & Others & 5 & 1.7 \\
\hline \multirow{2}{*}{$\begin{array}{l}\text { Health education about risks and benefits of traditional } \\
\text { medicine is important? }\end{array}$} & Yes & 261 & 90.3 \\
\hline & No & 22 & 7.6 \\
\hline \multirow{2}{*}{$\begin{array}{l}\text { Traditional medicines are more effective and safer than } \\
\text { modern health services }\end{array}$} & Yes & 108 & 37.4 \\
\hline & No & 177 & 61.2 \\
\hline
\end{tabular}

Respondents' practice related to traditional medicine. Table 4 showed majority of the respondents $246(85.1 \%)$ had used traditional medicine at least once. They reported oral products as the most widely used form of TM $223(77.2 \%)$, with many of them $198(68.5 \%)$ mentioning improvement in the outcome of therapy, although, some of them $11(3.8 \%)$ reported exacerbating outcomes with others 31 $(13.1 \%)$ indicating no change. Several participants preferred using both TM and modern medicine $111(38.4 \%)$ and more than half of the population $152(52.6 \%)$ said that the use of TM was mainly encouraged due to its availability and $27.0 \%$ linked it to the affordability of the products. About $50.3 \%$ of the study population had visited TM practitioners before the time study, with 78 (27.0\%) reporting visiting TM practitioners over a year ago, $64(22.1 \%)$ over 6 months ago, $35(12.1 \%) 2$ weeks ago and $3(1.0 \%)$ the day of filling this questionnaire. Figure 1 showed commonly used plants in herbal medicine, with neem and moringa plants being ranked as the most frequently used. 
Table 3: Attitude of participants of the study towards traditional medicine ( $\mathrm{N}=289)$

\begin{tabular}{|c|c|c|c|}
\hline & Variables & Frequency & $\%$ \\
\hline \multirow{2}{*}{$\begin{array}{l}\text { Do you have plan to use TM in the } \\
\text { future }\end{array}$} & Yes & 189 & 65.3 \\
\hline & No & 100 & 34.7 \\
\hline \multirow{4}{*}{$\begin{array}{l}\text { If No to question above, why don't } \\
\text { you have? }\end{array}$} & Access of modern medicine & 33 & 11.4 \\
\hline & Fear of side effect & 58 & 20.1 \\
\hline & Religion & 5 & 1.7 \\
\hline & Others & 14 & 4.8 \\
\hline \multirow{5}{*}{$\begin{array}{l}\text { Do you agree the usage of TM } \\
\text { among community? }\end{array}$} & Strongly agree & 71 & 24.6 \\
\hline & Agree & 123 & 42.6 \\
\hline & Neutral & 67 & 23.2 \\
\hline & Disagree & 23 & 8.0 \\
\hline & Strongly disagree & 5 & 1.7 \\
\hline \multirow{2}{*}{$\begin{array}{l}\text { Do you encourage others to use } \\
\text { TM? }\end{array}$} & Yes & 233 & 80.6 \\
\hline & No & 56 & 19.4 \\
\hline \multirow{4}{*}{$\begin{array}{l}\text { Why do you encourage others to use } \\
\text { TM? }\end{array}$} & Religion & 32 & 11.1 \\
\hline & Cost & 82 & 28.4 \\
\hline & Availability & 77 & 26.6 \\
\hline & Others & 49 & 17.0 \\
\hline \multirow{2}{*}{$\begin{array}{l}\text { Do you think that there are diseases } \\
\text { not cured by modern medicine? }\end{array}$} & Yes & 227 & 78.5 \\
\hline & No & 62 & 21.5 \\
\hline \multirow{2}{*}{$\begin{array}{l}\text { How do herbal medicine users } \\
\text { consider herbal medicine? }\end{array}$} & Herbal medicine is safe for use & 204 & 70.6 \\
\hline & Believe otherwise without reason, uncertain & 85 & 29.4 \\
\hline \multirow{3}{*}{$\begin{array}{l}\text { Why is herbal medicine is safe to } \\
\text { use }\end{array}$} & Their natural origin & 240 & 83.0 \\
\hline & Efficacy & 35 & 12.1 \\
\hline & Lack of adverse effect & 14 & 4.8 \\
\hline \multirow{2}{*}{$\begin{array}{l}\text { Do you accept traditional health } \\
\text { practitioners? }\end{array}$} & Yes & 239 & 82.7 \\
\hline & No & 50 & 17.3 \\
\hline
\end{tabular}

Table 4: Practice of the study subject on traditional medicine ( $\mathrm{N}=289)$

\begin{tabular}{|c|c|c|c|}
\hline & Variable & Frequency & $\%$ \\
\hline \multirow{2}{*}{$\begin{array}{l}\text { Have you ever used } \\
\text { TM products? }\end{array}$} & Yes & 246 & 85.1 \\
\hline & No & 43 & 14.9 \\
\hline \multirow{3}{*}{$\begin{array}{l}\text { In what form was the } \\
\text { TM product? }\end{array}$} & Oral & 223 & 77.2 \\
\hline & Topical & 14 & 4.8 \\
\hline & Others & 12 & 4.2 \\
\hline \multirow{3}{*}{$\begin{array}{l}\text { So what was the } \\
\text { outcome? }\end{array}$} & Improved & 198 & 68.5 \\
\hline & Exacerbated & 11 & 3.8 \\
\hline & No change & 38 & 13.1 \\
\hline \multirow{3}{*}{$\begin{array}{l}\text { Which one do you } \\
\text { prefer? }\end{array}$} & Traditional medicine & 81 & 28.0 \\
\hline & Modern medicine & 92 & 31.8 \\
\hline & Both & 111 & 38.4 \\
\hline \multirow{3}{*}{ Why do you prefer it? } & Its availability & 152 & 52.6 \\
\hline & Affordability & 78 & 27.0 \\
\hline & Others & 53 & 18.3 \\
\hline \multirow{2}{*}{$\begin{array}{l}\text { Have you ever visited } \\
\text { TM practitioner? }\end{array}$} & Yes & 146 & 50.5 \\
\hline & No & 135 & 46.7 \\
\hline \multirow{4}{*}{$\begin{array}{l}\text { When was the last } \\
\text { time you visited TM } \\
\text { practitioners? }\end{array}$} & One year ago & 78 & 27.0 \\
\hline & 6 months ago & 64 & 22.1 \\
\hline & 2 weeks ago & 35 & 12.1 \\
\hline & Today & 3 & 1.0 \\
\hline
\end{tabular}


T.L. Ohemu et al. / J. Pharmacy \& Bioresources 18(2), 147-154 (2021)

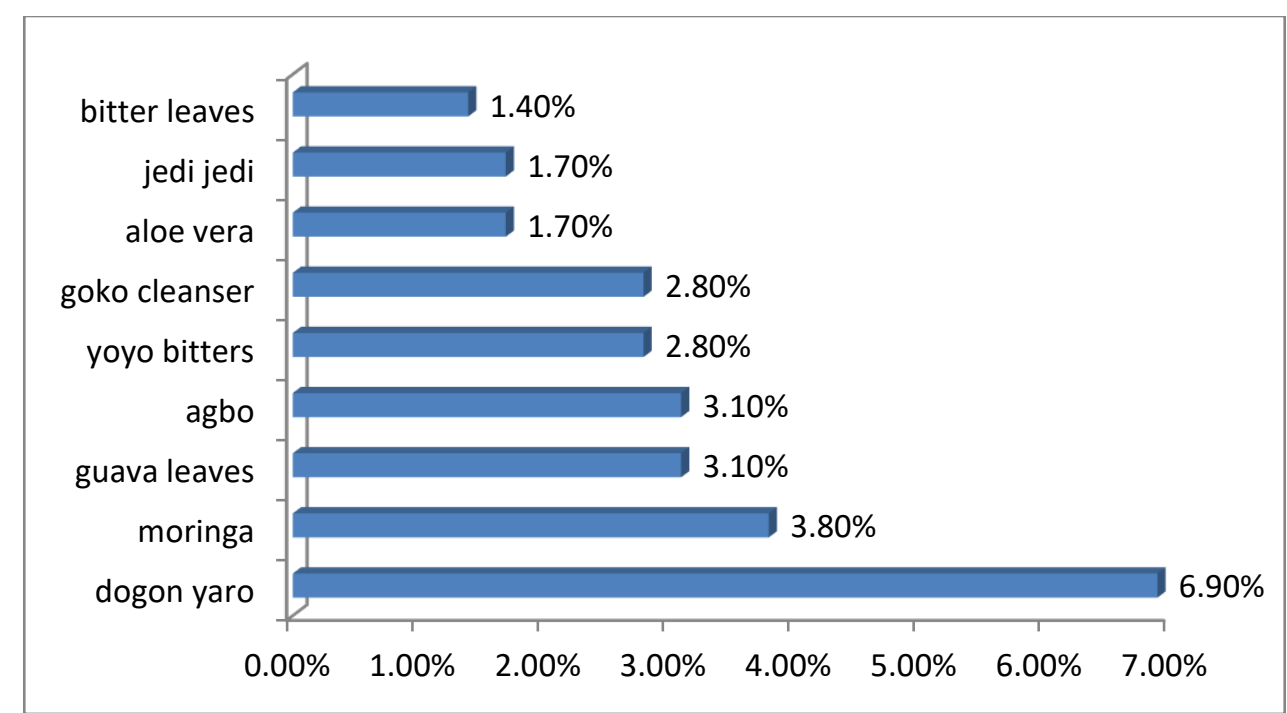

Figure 1: Top 9 commonly used herbal medicine

\section{DISCUSSION}

This cross-sectional study explored the knowledge, attitude and practice of traditional medicine usage in Jos South Local Government Area, Plateau State, Nigeria. The prevalence of TM use was $85.1 \%$. This finding is closely related to the study conducted in Ethiopia which indicated the prevalence of traditional medicine used as $80 \%$ [14]. The observed high prevalence in the present study could be due to fact that majority of the population accept $(82.7 \%)$ TM use due to its availability $(52.6 \%)$ and the belief that it is safe due to its natural origin $(83.0 \%)$. The age group of $19-28$ years formed the largest proportion $(55.7 \%)$ of the respondent of which $82.0 \%$ had ever used TM; and this was higher than the result of work done in Merawi town of Ethiopia [15].

Among the known TM, herbal medicine $(62.3 \%)$ was the most commonly used; and this agreed with outcome of a study conducted in urban areas of South-Western part of Nigeria, with herbal medicine prevalence of about $66.8 \%$ [16]. Similarly, the $80.6 \%$ acceptance of traditional medicine/practice among the study population was quite higher than the result obtained in a similar study done in Jara Town of Bale Zone, South East Ethiopia, which showed an almost equal percentage of $50.18 \%$ and $49.8 \%$ for those who accepted and those who did not accept, respectively [15]. The observed high response in acceptance in the present study could also be as a result of increasing adverts on radios and televisions with the notion that traditional medicine cures all illness, safe for use, no adverse effects, and or cost effective .

Majority of the respondent used TM mainly in the treatment of malaria and fever; this explains why neem tree ('dogonyaro') was most frequently used plant as shown in figure 1. A high percentage of the respondents 227 $(78.5 \%)$ agree to the fact that there are diseases that cannot be cured by modern medicine with HIV/AIDS and liver disease being the most mentioned as it was seen in the study done in Ethiopia. The reported high percentage on the safety of herbal medicine $(70.6 \%)$ among the users was consistent with the study done in Nigeria and Ethiopia [15, 16].

The reported high patronage of TM by majority $(85.1 \%)$ of the respondents with oral form as the highest dosage form used $(77.2 \%)$ was similar to the result of similar studies carried out in Bale zone, Mana Angetu district, Ethiopia[15, 17]. The high preference for the use of both traditional and modern medicine agreed with the outcome of a similar study carried out in Lagos, Nigeria where majority of 
the respondent also prefer to combine traditional and modern medicine [18].

\section{Conclusion}

This study revealed high prevalence of TM used in Jos South LGA, Plateau state and this could be related to the socio-cultural acceptability, easy accessibility, and affordability of the practice; and also due to the acclaimed safety and effectiveness of the products largely because of its natural origin,. The population had good knowledge of traditional medicine especially herbal medicine, especially in the management of fever and malaria.

\section{REFERENCES}

1. Calixto JB. The role of natural products in modern drug discovery. Annals of the Brazilian Academy of Sciences. 2019; 91(3): 1-7. https://doi.org/10.1590/0001-3765201920190105

2. Msomi NZ, Simelane MBC. Herbal Medicine. Intechopen Publisher. 2018, pp 216. DOI: 10.5772/intechopen.72816

3. Carvalho JCT. Market Analysis on Traditional Medicine-2020. Herbal Medicine. 2020; 6(2)

4. Samapth Kumar KP, Atheeq R, Ismail S. Herbal medicine. Indian Journal of Research in Pharmacy and Biotechnology. 2013; 1(2): 201-205.

5. Ekor M. The growing use of herbal medicines: issues relating to adverse reactions and challenges in monitoring safety. Frontiers in pharmacology. 2014; 4: 177. https://doi.org/10.3389/fphar.2013.00177

6. Thorsen RS, Pouliot M. Traditional medicine for the rich and knowledgeable: challenging assumptions about treatment-seeking behaviour in rural and periurban Nepal. Health Policy Plan. 2016; 31(3): 314324. doi:10.1093/heapol/czv060

7. Elujoba AA, Odeleye OM, Ogunyemi CM. Traditional medicine development for medical and dental primary healthcare delivery system in Africa.African Journal of Traditional, Comple mentary and Alternative Medicines. 2005; 2: 46-61.
8. Ezekwesili-Ofili JO, Okaka ANC. Herbal Medicines in African Traditional Medicine. In P.F. Builders (Ed.), Herbal medicine. 2019. pp.191-214. Intechopen. 10.5772/intechopen.80348 191-214.

9. Abbott R. Documenting traditional medical Knowledge. World Intellectual Property Organisation Publication. 2014. p. 5.

10. Fifty Sixth World Health Assembly, Agenda item 14.10, Traditional Medicine, WHA56.31, May 28, 2003 at 1, available at http://whqlibdoc.who.int/wha/2003/WHA56_31.pdf

11. WHO (2005). WHO Traditional Medicine Strategy 2000-2005.

12. Charan J, Biswas T. How to calculate sample size for different study designs in medical research? Indian J Psychol Med. 2013; 35(2):121-126. doi:10.4103/0253-7176.116232

13. National Population Commission (NPC) [Nigeria] and ICF. 2019. Nigeria Demographic and Health Survey 2018. Abuja, Nigeria, and Rockville, Maryland, USA: NPC and ICF.

14. Mohsen A, Masoumeh H. "Knowledge, attitude and practice toward complementary and traditional medicine among Kashan health care staff, 2012," Complementary Therapies in Medicine. 2014; 22(1):126-132.

15. Mohammed AY, Kasso M, Demeke A. Knowledge, Attitude and Practice of Community on Traditional Medicine in Jara Town, Bale Zone South East Ethiopia. Science Journal of Public Health. 2016; 4(3): 241-246. doi:10.11648/j.sjph.20160403.23.

16. Oreagba I, Oshikoya K, Amachree M. Herbal medicine use among urban residents in Lagos, Nigeria. BMC complementary and alternative medicine. 2011; 11:117. 10.1186/1472-6882-11-117.

17. Belachew N, Tadesse T, Gube AA. Knowledge, Attitude, and Practice of Complementary and Alternative Medicine among Residents of Wayu Town, Western Ethiopia. J Evid Based Complementary Altern Med. 2017; 22(4): 929935. doi: $10.1177 / 2515690 \times 17746547$

18. Agbaje EO, Babatunde EO. A KAP study of the attitude and practice of traditional medicine in a contemporary Nigerian community. Cent Afr J Med. 2005; 51(5-6): 58-62. 